\title{
Personal Learning Environments: Research-Based Practices, Frameworks and Challenges
}

\author{
Linda Castañeda ${ }^{1} \mathbb{B}$, Nada Dabbagh², Ricardo Torres-Kompen ${ }^{3}$ \\ 1University of Murcia, Spain \{lindaca@um.es\} \\ ${ }^{2}$ George Mason University, USA \{ndabbagh@gmu.edu\} \\ ${ }^{3}$ Universitat Ramon Llull - La Salle Barcelona Campus, Spain \{ricardot@salleurl.edu\} \\ Received on 26 December 2016; revised on 28 December 2016; accepted on 29 December 2016; published on 15 January 2016
}

DOI: 10.7821/naer.2017.1.229

(ब) DENC-ND

Personal Learning Environments (PLE), as a concept as well as an emerging practice, is not just one of the most innovative dimensions of technology-enabled student-centered learning, but also one of the most challenging disruptions to the institutional traditional conception of knowledge.

A PLE is usually described as a structure and process that helps learners organize the influx of information, resources and interactions that they are faced with on a daily basis into a personalized learning space or experience. In a PLE, the learner develops an individualized digital identity through the perceptual cues and cognitive affordances that the personal learning environment provides, such as what information to share and when, who to share it with, and how to effectively merge formal and informal learning experiences (Castañeda, Cosgrave, Marín, Cronin, 2016).

Events as the PLE Conference, which started in 2010, emerged as an answer to the need for showcasing, disseminating and sharing the novel and original research (and knowledge) specific to the PLE movement. Additionally, they were a departure from the traditional format of most conferences in that the attendees, who had developed individualized research-based PLE practice, came together in what we call the "spirit of PLEs": sharing, collaborating and creating together.

This past decade has seen a dramatic increase in the quantity of research published on PLEs and most of it has been enriched by the papers presented in the successive PLE events that have formed part of special issues of a diversity of journals, including Digital Education Review, the International Journal of Virtual and Personal Learning Environments, and others (Hernandez, 2016).

Thanks to the previous -and current- debate, experts are trying to understand what our relationship with the PLE concept is, and how it could help us improve the role of technology, people, communities, educational and information resources, cognitive mechanisms and so on, in learning. From these debates and discussions, witnessed at the PLE events and beyond, original discussions regarding institutional or non-institutional education have evolved into how to reconcile -pedagogically and technologically- learning inside and outside formal contexts.

Other discussions about technological and pedagogical perspectives have evolved to sociomaterial visions of learning recognising the reciprocal, recursive, and transformative interaction between people and technology.
The network, the impact -and training- of metacognition, the horizontal organisation, are emerging and ongoing topics that are enriching the learning debate and forcing new explorations in research and practice. Such investigations will focus more on people and their relationship with technology and less on the use of technology for automating the learning experience.

On the one hand, it seems that PLE is no longer the centre of the discussion, at least not as a standalone construct. But, on the other hand, PLE is more than ever the paradigm for supporting new learning models for the digital times.

PLEs have had direct implications on Massive Open Online Courses (MOOCs), adaptive learning, and learning analytics, to name a few new learning models and processes that have personalization of learning at their core. MOOCs have been characterised as PLE-type environments providing learners with the appropriate tools to engage in self-directed and personalised learning and integrating social media features to boost opportunistic interaction and informal exchanges between students (Gillet, 2013; Kop \& Fournier, 2014). PLEs are also relying on analytics to support adaptive learning or personalised learning paths. PLE components such as a personal profiler, a content aggregator, a recommender, a progress tracker, and the ability to identify learning goals and link to social networks around shared goals, is enabling learners to define, develop and configure learning spaces and experiences for themselves and for the audience they choose.

This Special Issue examines some of the current visions of personalised learning from the perspective of PLE. Personalization takes centre stage as one of the key processes developed at any level of the human life experience and understanding it is even more crucial now given the prevalence of communication and adaptive technologies.

In their article, "Multimedia and Textual Reading Comprehension: Multimedia as Personal Learning Environment's Enriching Format”, Garcia, Rigo \& Jimenez, analyse how audio-visual reading would influence the general comprehension reading process in secondary school students, and how this audio-visual and multimedia approach would enrich their personal learning experience in the building of their PLE.

Kuhn, in her article "Are students ready to (re)-design their Personal Learning Environment? The case of the EDynamic.Space”, examines student preparedness to use digital technologies for learning and proposes that engaging students in the act of dynamically designing and implementing a PLE to 
support their learning experience could lead to improvement in digital literacy and capability. Kuhn concludes that there are three main areas required to achieve digital fluency and to enable students to benefit from being active in the digital domain: attitude towards technology, knowledge about the capabilities of technology in an academic context, and skills to effectively use technology for learning.

In their article, "Learning in Online Continuing Professional Development: An Institutionalist View on the Personal Learning Environment”, Johnson, Prescott and Lyon explore one of those still hidden areas of Personal Learning Environments: the development of formal learning initiatives in the context of the PLE awareness. Authors studied data (interactions) around a professional development course and get some suggesting conclusions that invite to reconsider pedagogy in terms of learning transactions -and constraints- for students, how they are going further the courses "walls" and what would be some of the questions that we must propose around them.

Dabbagh and Fake, in their article "College Students' Perceptions of Personal Learning Environments (PLEs) Through the Lens of Digital Tools, Processes and Spaces” examine how students use digital tools to personalize learning and what would their ideal PLEs look like. The authors discuss the findings of the study which revealed that students did not find digital technology very effective in supporting the creation of PLEs and that their ideal PLE would include opportunities for discussion, collaboration and interaction, tools for organizing, planning, and resource management, experiential learning strategies. Their conclusions remark the importance of self-reflection, thinking skills and other learner competencies in the conceptualizing and developing of the personal learning environment.

We do not know what the future holds for the PLE events, and it will probably be re-invented in a new format, but the idea will keep on going. The selection of papers for this issue, shows the potential of PLEs and the work that is still to be done in the field. It will be centered on exploring practices, researching, and engaging in new debates that could improve our understanding of the emerging ideas that are challenging learning contexts inside our institutions and beyond.

In addition to these articles, this issue contains six articles related to other interesting points of view and research about learning, that we are sure you will find provocative.

Firstly, Amiripour, Dossey \& Shahvarani analyze the potential for curricular innovation in mathematics of three primary education centers located in Tehran (Iran) with their paper "Impact of Organizational Inertia and Dynamic Capabilities on Educational Performance of the Charitable Societies and Its Impact on Mathematical Performance of Elementary At-Risk Students.”

Fernández Santín \& Feliu Torruella’s paper, "Reggio Emilia: An Essential Tool to Develop Critical Thinking in Early Childhood," provides a new conceptual framework for artistic education during the Infant Education stage.

Loaiza, Paola, Abarca \& Salazar show the results obtained through the implementation of a model to diagnose the innovative capacity of Ecuadorean universities in their paper "Determination of the Innovative Capacity of Ecuadorian Universities."

In turn, the article written by Martos-Garcia, Usabiaga \& Valencia-Peris -"Students' Perception on Formative and Shared Assessment: Connecting two Universities through the Blogosphere"- assesses university students' perception about an innovative practice based on a formative peer-to-peer evaluation through the blogosphere.

The article "The Intercultural Sensitivity of Chilean Teachers Serving an Immigrant Population in Schools," authored by Morales, Sanhueza, Friz \& Riquelme examines the attitude of Chilean teachers towards interculturality in the different educational levels.

Finally, Merma Molina, Peña Alfaro \& Peña Alfaro González focus on research dissemination through the design of an instrument meant to assess the extent to which scientific papers adapt to the American Psychological Association rules. They present this proposal in the article entitled "Design and Validation of a Rubric to Assess the Use of American Psychological Association Style in scientific articles.”

Linda Castañeda University of Murcia

Nada Dabbagh George Mason University

Ricardo Torres-Kompen Universitat Ramon Llull - La Salle Barcelona Campus

\section{REFERENCES}

Castañeda, L., Cosgrave, M., Marín, V., \& Cronin, C. (2016). Personal Learning Environments: PLE Conference 2015 Special Issue Guest Editorial. Digital Education Review, 29. Retrieved from http://greav.ub.edu/der

Gillet, D. (2013). Personal Learning Environments as enablers for connectivist MOOCs. In Proceedings of the 12th International Conference on Information Technology Based Higher Education and Training (pp. 1-5). Antalya, Turkey. doi:10.1109/ithet.2013.6671026

Hernández, M. A. (2016). Gestión del conocimiento, actividad científica y entornos personales de apredizaje (PLEs): una bibliometría de la PLE conference. Edutec. Revista Electrónica de Tecnología Educativa, O(55). doi:10.21556/edutec.2016.55.653

Kop, R., \& Fournier, H. (2014). Developing a framework for research on Personal Learning Environments. E-learning in Europe Journal, 35.

\section{How to cite this article:}

Castañeda, L.; Dabbagh, N. \& Torres-Kompen, R.. (2017). Personal Learning Environments: Research-Based Practices, Frameworks and Challenges. Journal of New Approaches in Educational Research, 6(1), 1-2. doi: 10.7821/naer.2017.1.229 